\section{Detection of human immunod- eficiency virus type 1 transmit- ted drug resistance among treatment-naive individuals residing in Jakarta, Indonesia}

\author{
Siti Qamariyah Khairunisa,, ,2 Ni Luh \\ Ayu Megasari, ${ }^{2}$ Retno Pudji Rahayu, ${ }^{2}$ \\ Adiana Mutamsari Witaningrum, ${ }^{2}$ \\ Shuhei Ueda, ${ }^{2,3,4}$ Muhammad Qushai \\ Yunifiar M, ${ }^{2}$ Dwi Wahyu Indriati, ${ }^{2,6}$ \\ Tomohiro Kotaki, ${ }^{3}$ Adria Rusli, ${ }^{5}$ \\ Nasronudin, ${ }^{2,7}$ Masanori Kameoka ${ }^{2,3,4}$ \\ 'Doctoral Program,Faculty of Medicine, \\ Universitas Airlangga, Surabaya; \\ ${ }^{2}$ Indonesia-Japan Collaborative \\ Research Centre for Emerging and Re- \\ emerging Infectious Diseases (CRC- \\ ERI), Institute of Tropical Disease, \\ Universitas Airlangga, Surabaya, \\ Indonesia; ${ }^{3}$ Department of Public \\ Health; ${ }^{4}$ Center for Infectious Diseases, \\ Kobe University Graduate School of \\ Medicine, Hyogo, Japan; ${ }^{5}$ Sulianti \\ Saroso Hospital, Jakarta, Indonesia \\ ${ }^{6}$ Department of Health, Vocational \\ Faculty; ${ }^{7}$ Airlangga Hospital, \\ Universitas Airlangga, Surabaya, \\ Indonesia
}

\begin{abstract}
The presence of transmitted drug resistance (TDR) in human immunodeficiency virus type 1 (HIV-1) infected individuals naive to antiretroviral therapy, may affect the effectiveness of treatment. Jakarta, the capital city of Indonesia, recorded the highest number of cumulative HIV infection cases in the country. This study aimed to identify on the appearance of TDR, as well as to identify HIV-1 subtypes circulating among treatment-naive individuals in Jakarta. Whole blood samples collected from 43 HIV-1 infected, treatment-naive individuals. Viral subtyping and drug resistance testing were performed on HIV-1 pol genes amplified using nested polymerase chain reaction. CRF01_AE was detected most frequently in Jakarta (73.08\%). Drug resistance-related major mutation was not detected in protease fragments of pol gene, but two major mutations, K103N (6.67\%) and Y181C (6.67\%), were detected in reverse transcriptase fragments of pol gene. Our results suggest that TDR was emerged in Jakarta at a certain extent, thus further surveillance study to monitor the TDR prevalence and circulating HIV-1 subtypes in this region is considered to be necessary.
\end{abstract}

\section{Introduction}

Indonesia reported increasing cases of human immunodeficiency virus (HIV) infections each year. The country recorded 280,623 cumulative cases of HIV infection in 2017, with 48,300 new cases among them. ${ }^{1}$ Indonesia contributed to $18 \%$ of new HIV infection and 23\% acquired immune deficiency syndrome (AIDS)-related deaths in Asia and the Pacific. ${ }^{2}$ Jakarta, the capital city of Indonesia, has the highest number of cumulative HIV-infection cases in the country. The city recorded a total of 51,981 HIV cases, with 9,215 AIDS cases. ${ }^{1}$

As many other countries, HIV infection in Indonesia is mainly caused by HIV type 1 (HIV-1) group M. There are nine subtypes (A, B, C, D, F, G, H, J, and K), as well as circulating recombinant forms (CRFs) and unique recombinant forms (URFs), within the group M. ${ }^{3}$ Several studies have reported the dominance of HIV-1 CRF01_AE in several Indonesian regions. ${ }^{4-10}$

As an effort to address the HIV epidemic, Ministry of Health of Indonesia implemented antiretroviral therapy (ART) under national guideline. First-line ART regimen recommended contains two nucleoside reverse transcriptase (RT) inhibitors (NRTIs) and one non-nucleoside RT inhibitor (NNRTI). Zidovudine (AZT), lamivudine (3TC), tenofovir (TDF), and emtricitabine (FTC) are commonly used NRTI in Indonesia, while nevirapine (NVP) and efavirenz (EFV) are commonly used NNRTI. For HIV-1-infected individuals suffering treatment failure despite high adherence to ART, second-line regimen employing two NRTIs and one ritonavirboosted protease (PR) inhibitor (PI) is recommended. ${ }^{11}$

ART strongly suppresses viral replication and maintain a healthy condition of infected individuals on ART; however, the presence of drug resistant viruses might compromise treatment success. ${ }^{12}$ The emergence of acquired drug resistance (ADR) in treatment-experienced individuals and transmitted drug resistance (TDR) in treatment-naive individuals residing in several Indonesian regions, including Surabaya, Riau, Bali, and Maumere, has been previously described..$^{5-10}$ The TDR might disrupt effectiveness of treatment, resulting in unfavorable clinical outcomes. ${ }^{13}$ Therefore, it is important to monitor the emergence of TDR by a continuous surveillance in order to secure long-term and stable ART in Indonesia.

The United Nations Development Program recently categorized Indonesia as a lower middle-income country. ${ }^{14}$ In such low- and middle-income countries, the
Correspondence: Masanori Kameoka, Department of Public Health, Kobe University Graduate School of Health Sciences, 7-10-2 Tomogaoka, Suma-ku, Kobe, Hyogo 6540142, Japan.

Tel.: +81787964594 - Fax: +81787964509

E-mail: mkameoka@port.kobe-u.ac.jp

Key words: ART-naive individuals, HIV/AIDS, transmitted drug resistance.

Contributions: SQK performed molecular analyses and drafted the manuscript, as well as involved in the design and coordination of the study; AMW and NLAM performed molecular analyses and helped in drafting the manuscript; SU, MQYM, DWI, and TK performed molecular analyses; RPR, AR, PW, and N were involved in the design and coordination of the study; MK conceived the study, involved in the design and coordination. All authors read and approved the final version of the manuscript.

Conflict of Interest: the authors declare no potential conflict of interests.

Funding: This research was funded by the program of the Japan Initiative for Global Research Network on Infectious Diseases (JGRID) from the Ministry of Education, Culture, Sport, Science and Technology in Japan, and the Japan Agency for Medical Research and Development (AMED).

Acknowledgements: This research was supported by the program of the Japan Initiative for Global Research Network on Infectious Diseases (J-GRID) from the Ministry of Education, Culture, Sport, Science and Technology in Japan, and the Japan Agency for Medical Research and Development (AMED); and the Center of Excellence (COE) program for the Institute of Tropical Disease by the Ministry for Research and Technology (RISTEK) of Indonesia supported the study. Medical English Services (Kyoto, Japan) proofread the manuscript prior to the submission.

Received for publication: 17 February 2020. Accepted for publication: 1 July 2020.

This work is licensed under a Creative Commons Attribution-NonCommercial 4.0 International License (CC BY-NC 4.0).

(C) Copyright: the Author(s), 2020

Licensee PAGEPress, Italy

Infectious Disease Reports 2020; 12(s1):8740

doi:10.4081/idr.2020.8740

emergence of TDR would likely hamper efficient ART since drug resistance testing for TDR monitoring is generally not widely available at clinical sites. ${ }^{15}$ It is aimed to identify the presence of HIV-1 TDR among treatment-naive individuals residing in 
Jakarta, Indonesia, and also to clarify the currently circulating HIV-1 subtype/CRFs in the region.

\section{Materials and Methods}

\section{Demographic characteristics of study participants}

Procedures employed in this study were approved by ethical committee of Kobe University Graduate School of Medicine (approval number: 784) prior the commencement of the study. Forty-three HIV-1 infected individuals at the Sulianto Saroso Hospital in Jakarta were enrolled in this study. Written informed consent was provided by each individual prior to sample collection. Treatment-naive status was confirmed by medical records. Peripheral blood samples were collected from each participant. Peripheral blood mononuclear cells were then isolated from samples by a density gradient centrifugation using the $\mathrm{BD}$ Vacutainer CPT Tube (Becton, Dickinson and Company, Franklin Lakes, NJ, USA), and subjected to DNA extraction using QIAamp DNA Blood Mini Kit (Qiagen, Hilden, Germany).

\section{HIV-1 Genotyping Analysis}

Amplification of HIV-1 PR and RT genes were conducted by a nested polymerase chain reaction (PCR) using the Gotaq green master mix (Promega, Madison, WI, USA) or Ex Taq (Takara Bio, Shiga, Japan) and primer sets described previously. ${ }^{6}$ Primer sequences are available upon request. We carried out a limiting dilution of DNA samples, and endpoint PCR amplicon which may be from the major population of virus in infected individuals were subjected to sequencing analysis using the BigDye Terminator v3.1 Cycle Sequencing kit (Applied Biosystems, Foster City, CA, USA) and the ABI PRISM 3500 $\mathrm{xl}$ genetic analyzer (Applied Biosystems, Foster City, CA, USA). Viral sequence data were assembled and aligned using Genetyx version 10 software (Genetyx, Tokyo, Japan). The Recombinant Identification
Program (RIP) available on Los Alamos National Laboratory website (www.hiv.lanl.gov/) was utilized for HIV-1 subtyping. As an addition, phylogenetic analysis using a neighbor-joining (NJ) method with Kimura two-parameter model were performed by using MEGA6.2 software. ${ }^{16}$ If there was an incompatibility in the results of viral subtyping between the PR and RT genes of one sample, the viral genomic fragments were considered to be derived from a recombinant virus. Detection of drug resistance-related mutations against antiretroviral drugs was carried out according to the drug resistance mutations panel of the International Antiviral Society-United States of America (IAS-USA), as well as the World Health Organization (WHO) surveillance list. The presence of at least one drug resistancerelated major mutation was defined as TDR. ${ }^{17}$ Sequence data were deposited in the GenBank database with accession numbers MH200718 - MH200738, MH200709MH200717, MK927045 - MK927049, and MK937919.

\section{Results \\ HIV-1 subtyping}

We successfully sequenced 21 fulllength, 297-bp PR genes [corresponding to nucleotide (nt) 2253 - 2549 of a HIV-1 subtype B reference strain, HXB2 (GeneBank accession no. K03455)] and the N-terminal region of 43 RT genes (729 bp, nt 2583 3311). The results of viral subtyping were mostly consistent between RIP and phylogenetic analysis; however, in the case of contradictions between these analyses, the results of the phylogenetic analysis were taken (data not shown). As the results, CRF01_AE was found to be a predominant HIV-1 subtype in Jakarta (19/26, 73.08\%), followed by recombinant forms containing subtype B and CRF01_AE genomic fragments $(5 / 26,19.23 \%)$ and a recombinant form containing subtype $\mathrm{G}$ and CRF01_AE genomic fragments $(1 / 26,3.85 \%)$, and sub- type B (1/26, 3.85\%) (Figure 1). These results suggest that CRF01_AE was the predominant CRF in Jakarta, similar to other regions in Indonesia. ${ }^{4-9}$

\section{Prevalence of TDR in RT and PR Genes}

Identification of TDR using the drug resistance mutation panel of the IAS-USA and WHO surveillance list shown the presence of at least one drug resistance-related major mutations in 2 of 43 RT genes (data not shown). Therefore, the overall prevalence of TDR was calculated to be $4.65 \%$. Two major mutations against NNRTIs, $\mathrm{K} 103 \mathrm{~N}$ and $\mathrm{Y} 181 \mathrm{C}$, were detected in peripheral blood samples derived from 2 patients, SS21 and SS41 (Table 1). These mutations affect viral susceptibilities to EFV, NVP, etravirine (ETR), and RPV (Table 1). CRF01_AE was detected in both samples (data not shown). Despite no drug resistance-related major mutations were identified, several drug resistance-related minor mutations including M36I [amino acid substitution from methionine $(\mathrm{M})$ to isoleucine (I) at position 36 in the PR gene] (85.71\%), H69K (85.71\%), L89M (76.19\%), K20R (57.14\%), and G16E $(47.62 \%)$, were detected in the PR genes (Table 1). These mutations potentially affect viral susceptibilities to PIs, such as ritonavir-boosted atazanavir, ritonavirboosted darunavir, ritonavir-boosted fosamprenavir, ritonavir-boosted indinavir, ritonavir-boosted lopinavir, nelfinavir, ritonavirboosted saquinavir, and ritonavir-boosted tipranavir. ${ }^{17}$ The detection of drug resistance-related mutations was carried out based on the drug resistance mutations list of the IAS-USA (International Antiviral Society - United States of America). Bold letters denote drug resistance-related major mutations. ATV/r, ritonavir-boosted atazanavir; EFV, efavirenz; ETR, etravirine; $\mathrm{FPV} / \mathrm{r}$, ritonavir-boosted fosampenavir; $\mathrm{IDV} / \mathrm{r}$, ritonavir-boosted indinavir; LPV/r, ritonavir-boosted lopinavir; NFV, nelfinavir; NVP, nevirapine; RVP, rilpivirine; $\mathrm{SQR} / \mathrm{r}$, ritonavir-boosted saquinavir; $\mathrm{TPV} / \mathrm{r}$, ritonavir-boosted tipranavir.

Table 1. Drug resistance-related mutations detected in pol genes encoding protease and reverse transcriptase derived from treatmentnaïve individuals residing in Jakarta, Indonesia.

\begin{tabular}{lccc} 
Gene & Mutation & Frequency (\%) & Resistance to \\
Protease & L10IN & 27.3 & ATV, IDV, NFV, FPV, LPV, SQR \\
& L33F & 4.5 & ATV, DRV, LPV, TPV \\
K20I & 4.5 & ATV \\
Reverse transcriptase & K103N & 6.67 & EFV, NVP \\
& Y181C & 6.67 & EFV, ETR, NVP, RPV \\
\hline
\end{tabular}




\section{Discussion}

Viral subtyping and genotypic drug resistance analyses were combined in the present study to elucidate the genotypic characterization of HIV-1 variants circulating in Jakarta, Indonesia. Subtyping results were consistent with previous studies. ${ }^{4-9}$ The CRF01_AE was found to be a predominant CRF among HIV-infected treatmentnaive individuals in Jakarta. The CRF is known to predominantly circulate in Southeast-Asian countries, including Thailand and Malaysia, ${ }^{18,19}$ as well as in East-Asian countries, including Taiwan, China, South Korea, and Japan. ${ }^{20}$ These findings indicate the increase of worldwide prevalence of CRF01_AE viruses. In addition, a study in China observed faster dis- ease progression due to HIV-1 CRF01_AE infection. ${ }^{21}$ The CRF01 AE virus was also associated with faster decline of CD4 and higher prevalence of CXCR4-tropic variants; ${ }^{22}$ however, in the present study, CD4 data was not available. Therefore, the association of CRF01_AE infection and disease status was not clear in Indonesia. A recombinant virus containing subtype $G$ and CRF01_AE genomic fragments was detected. Subtype $G$ virus is not commonly prevalent in Indonesia and other Southeast Asian countries; therefore, it might be emerged from other region of the world. Continuous surveillance studies to monitor circulating subtypes and CRFs of HIV-1 in Indonesia are required.

Unlike ADR in ART-experienced individuals which is related to prolong use of
ART and unplanned treatment interruption due to lack of adherence or inaccessible ART, TDR in ART-naive individuals is resulted from transmission of drug resistant strain. ${ }^{23,24}$ Due to the occurrence of TDR, a newly HIV-1-infected individuals may carry a drug resistant virus without yet receiving ART. ${ }^{15}$ In this study, the detection rate of TDR against RT inhibitors was low $(2 / 43,4.65 \%)$, which was consistent to the results our previous study conducted in Surabaya, Indonesia $(4.3 \%, 2 / 47) .{ }^{5} \mathrm{HIV}$ prevention trial conducted in Indonesia, Vietnam, and Ukraine (HTPN 074) revealed the presence of HIV major DRMs among $24.1 \%(27 / 112)$ injecting drug users in Jakarta; ${ }^{25}$ thus the transmission of HIV drug resistant strain might be possible to occur, resulting in the presence of RT inhibitors
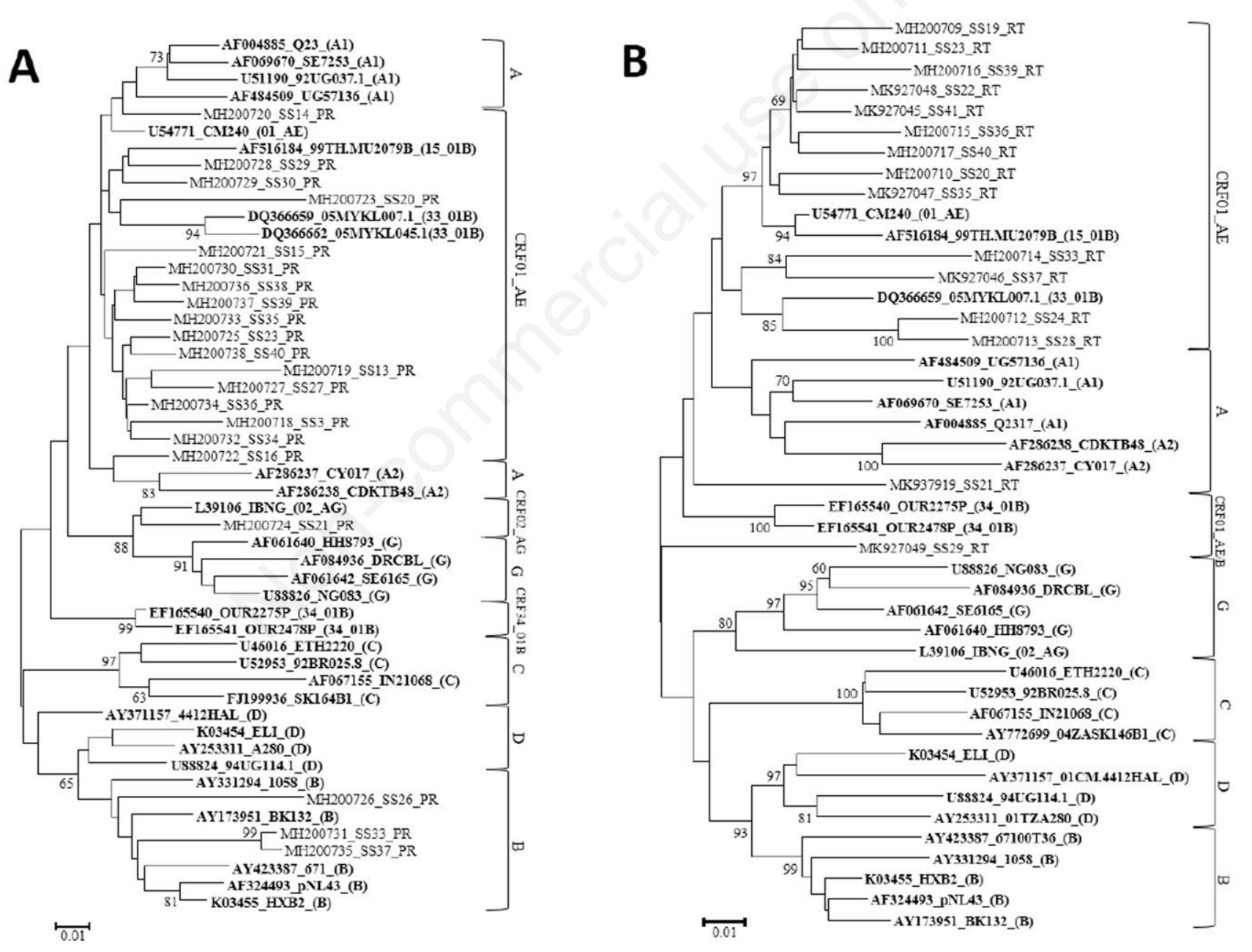

Figure 1. Phylogenetic tree analysis of HIV-1 pol genes encoding viral RT and PR derived from treatment-naive individuals residing in Jakarta, Indonesia. NJ trees were constructed on HIV-1 pol genes encoding protease (A) and reverse transcriptase (B). HIV-1 genomic fragments derived from subtypes A1, A2, B, C, D, and G reference strains, as well as CRF01_AE, CRF02_AG, CRF15_01B, CRF33_01B, and CRF34_01B reference strains were included in the analysis (in bold). The sample IDs are shown as combinations of a GeneBank accession number, sample ID, and the assigned subtype or CRF of the reference strain (shown in parentheses) in that order. Bootstrap values were mentioned when the value is more than 70 . 
TDR among ART-naive individuals residing in Jakarta.

Samples from SS21 and SS41 contained $\mathrm{K} 103 \mathrm{~N}$ and $\mathrm{Y} 181 \mathrm{C}$ mutations that conferred viral resistance against EFV and NVP. ${ }^{17}$ Detection of K103N as a TDR was consistent to the finding of the same mutation as the most frequent NNRTI-related drug resistance mutation found in Surabaya, Indonesia. $^{5}$

Compared to studies conducted in other countries, similar results were found in China. Low TDR prevalence $(3,6 \% ;<5 \%)$, the presence of $\mathrm{K} 103 \mathrm{~N}$, and high prevalence of CRF01_AE in China were reported by Zhao et al. in $2018 .{ }^{26}$ On the contrary, higher TDR prevalence was found in European countries and the United States; however, higher rate of $\mathrm{K} 103 \mathrm{~N}$ mutation was observed among Indonesian individuals recently infected with HIV-1.27,28 ART expansion in Indonesia may be related with the high prevalence of $\mathrm{K} 103 \mathrm{~N}$ and $\mathrm{Y} 181 \mathrm{C}$, because NVP and EFV are used in the firstline ART regimens in this country. In contrast, TDR to PIs is less common, possibly due to less frequent use of the drugs in Indonesia. In the present study, no TDR against PIs was detected, while minor mutations, M36I (85.71\%), H69K (85.71\%), L89M $(76.19 \%)$, K20R $(57.14 \%)$, and G16E (47.62\%), were frequently detected among $85.71 \%$ of PR genes (Table 1). These mutations have been identified as natural polymorphisms among CRF01 AE viruses. ${ }^{29}$ This result is also consistent with previous findings showing the absence of TDR against PR inhibitors in Indonesia ${ }^{5}$. The presence of minor PI mutations is considered to have no effect on therapy outcome in HIV-infected individuals. No difference was found between individuals with and without minor PI mutations in regards of time to viral suppression. Thus, PIs can be incorporated into the regimen of HIVinfected individuals with minor PI mutations when needed. ${ }^{30}$

The WHO classifies TDR into three categories: low $(<5 \%)$, moderate $(5-15 \%)$ and high $(>15 \%)$ prevalence. When the prevalence is low, $(<5 \%)$, the national ART program should function optimally. When moderate $(5-15 \%)$ prevalence is detected, the WHO advices public health action, such as examining specific ART practice practices and drug quality measures for specific drug classes for which prevalence is $>5 \%$, increasing support to ART programs to minimize the emergence of drug resistance in treatment and prevention programs to minimize the TDR. In addition, if high (>15\%) prevalence is found, the WHO advises strong public health action, such as increased surveillance and a change in first- line ART regimens. In our study, no TDR was detected for PIs, while low prevalence $(<5 \%)$ of TDR for RT inhibitors was found in Jakarta, indicating optimal implementation of national ART program in the aforementioned region.

\section{Conclusion}

CRF01_AE is a predominant CRF circulating in Jakarta. In addition, as a minor CRF in Southeast Asia, recombinant variants containing subtype $G$ and CRF01_AE gene fragments were detected. The appearance of TDR was lower than 5\%. The drug resistance-associated major mutations, K103N (6.67\%) and Y181C (7.14\%), were detected in RT genes, suggesting the emergence of TDR in Jakarta. It is conceivable that consider that surveillance on HIV-1 subtypes/CRFs as well as on the emergence of TDR to be required in this region.

\section{References}

1. Ministry of Health of Indonesia (Kementerian Kesehatan Republik Indonesia). Laporan Situasi Perkembangan HIV-AIDS \& PIMS di Indonesia Januari-Desember 2017. Jakarta: Ministry of Health of Indonesia; 2018. Available from: http://siha.depkes.go.id/portal/files_upl oad/Laporan_HIV_AIDS_TW_4_Tahu n $2017 \quad 1$ 1.pdf

2. Joint United Nations Programme on HIV/AIDS (UNAIDS). UNAIDS Data 2018. Geneva: Joint United Nations Programme on HIV/AIDS; 2018. Available from: www.unaids.org/ sites/default/files/media_asset/unaidsdata-2018_en.pdf

3. Hemelaar J, Gouws E, Ghys PD, Osmanov S. Global trends in molecular epidemiology of HIV-1 during 20002007. AIDS 2011;25:679-689.

4. Kotaki T, Khairunisa SQ, Sukartiningrum SD, et al. High prevalence of HIV-1 CRF01_AE viruses among female commercial sex workers residing in Surabaya, Indonesia. PLoS One 2013;8:e82645.

5. Kotaki T, Khairunisa SQ, Witaningrum AM, et al. HIV-1 transmitted drug resistance mutations among antiretroviral therapy-Naïve individuals in Surabaya, Indonesia. AIDS Res Ther 2015;12:5.

6. Khairunisa SQ, Ueda S, Witaningrum $\mathrm{AM}$, et al. Genotypic Characterization of Human Immunodeficiency Virus
Type 1 Prevalent in Kepulauan Riau, Indonesia. AIDS Res Hum Retroviruses 2018;34:555-560.

7. Khairunisa SQ, Masyeni S, Witaningrum AM, et al. Genotypic characterization of human immunodeficiency virus type 1 isolated in Bali, Indonesia in 2016. HIV AIDS Rev 2018;17:81-90.

8. Indriati DW, Kotaki T, Khairunisa SQ, et al. Appearance of Drug Resistance Mutations Among the Dominant HIV-1 Subtype, CRF01_AE in Maumere, Indonesia. Curr HIV Res 2018;16:158166.

9. Megasari NLA, Oktafiani D, Ana EF, et al. Genotypic Characterization of Human Immunodeficiency Virus Type 1 Isolated from Antiretroviral TreatmentExperienced Individuals in Buleleng Regency, Bali, Indonesia. AIDS Res Hum Retroviruses 2019;35:769-774.

10. Megasari NLA, Oktafiani D, Fitriana E, et al. The Emergence of HIV-1 Transmitted Drug Resistance Mutations Among Antiretroviral Therapy-naive Individuals in Buleleng, Bali, Indonesia. Acta Med Indones 2019;51:197-204.

11. Indonesia Ministry of Health Regulation. Peraturan Menteri Kesehatan Republik Indonesia Nomor 87 Tahun 2014 tentang Pedoman Pengobatan Antiretroviral. In Berita Negara Republik Indonesia Tahun 2015 Nomor 72. Available from: siha.depkes.go.id/portal/files_upload/Buku_Per menkes ARV Cetak.pdf

12. Fibriani $A$, Wisaksana $R$, Indrati $A$, et al. Virological failure and drug resistance during first-line anti-retroviral treatment in Indonesia. J Med Virol 2013;85:1394-1401.

13. Pillay D, Bhaskaran K, Jurriaans S, et al. The impact of transmitted drug resistance on the natural history of HIV infection and response to first-line therapy. AIDS 2006;20:21-28.

14. United Nations Development Programme (UNDP) in Indonesia; 2019. Available from: http://www.id.undp.org/content/indonesia/en/home/countryinfo.html

15. Pennings PS. HIV Drug Resistance: Problems and Perspectives. Infect Dis Rep 2013;5:e5.

16. Tamura K, Stecher G, Peterson D, et al. MEGA6: Molecular Evolutionary Genetics Analysis version 6.0. Mol Biol Evol 2013;30:2725-2729.

17. Wensing AM, Calvez V, Günthard HF, et al. 2017 Update of the Drug Resistance Mutations in HIV-1. Top Antivir Med 24:132-133. 
18. Chook JB, Ong LY, Takebe Y, et al. Molecular detection of HIV-1 subtype B, CRF01 AE, CRF33 01B, and newly emerging recombinant lineages in Malaysia. Am J Trop Med Hyg 2015;92:507-512.

19. Angelis K, Albert J, Mamais I, et al. Global Dispersal Pattern of HIV Type 1 Subtype CRF01_AE: A Genetic Trace of Human Mobility Related to Heterosexual Sexual Activities Centralized in Southeast Asia. J Infect Dis 2015;211:1735-1744.

20. Dey SK, Zahan N, Afrose S, et al. Molecular epidemiology of HIV in Asia. HIV AIDS Rev 2014;13:33-39.

21. Chu M, Zhang W, Zhang X, et al. HIV1 CRF01_AE strain is associated with faster HIV/AIDS progression in Jiangsu Province, China. Sci Rep 2017;7:1570.

22. Song H, Ou W, Feng Y, et al. Disparate impact on CD4 $\mathrm{T}$ cell count by two distinct HIV-1 phylogenetic clusters from the same clade. Proc Natl Acad Sci U S A 2019;116:239-244.

23. Stadeli K, Richman DD. Rates of emergence of HIV drug resistance in resource-limited settings: a systematic review. Antivir Ther 2013;18:115-123.

24. Pennings PS. Standing genetic variation and the evolution of drug resistance in HIV. PLoS Comput Biol 2012;8:e1002527.

25. Palumbo P, Zhang Y, Fogel J, et al. HIV drug resistance in persons who inject drugs enrolled in an HIV prevention trial in Indonesia, Ukraine, and Vietnam: HPTN 074. PLoS One 2019; 14:e0223829.

26. Zhao S, Feng Y, Hu J, et al. Prevalence of Transmitted HIV drug resistance in antiretroviral treatment-naïve newly diagnosed individuals in China. Sci Rep 2018;8:12273.

27. Hofstra LM, Sauvageot N, Albert J, et al. Transmission of HIV Drug
Resistance and the Predicted Effect on Current First-line Regimens in Europe. Clin Infect Dis 2016;62:655-663.

28. Levintow SN, Okeke NL, Hué S, et al. Prevalence and Transmission Dynamics of HIV-1 Transmitted Drug Resistance in a Southeastern Cohort. Open forum Infect Dis 2018;5(:ofy178.

29. Auwanit W, Isarangkura-Na-Ayuthaya P, Kasornpikul D, et al. Detection of drug resistance-associated and background mutations in human immunodeficiency virus type 1 CRF01_AE protease and reverse transcriptase derived from drug treatment-naive patients residing in central Thailand. AIDS Res Hum Retroviruses 2009;25:625-31.

30. Scherrer AU, Ledergerber B, von Wyl $\mathrm{V}$, et al. Minor protease inhibitor mutations at baseline do not increase the risk for a virological failure in HIV-1 subtype B infected patients. PLoS One 2012; 7:e37983. 